\title{
Analysis of Twitter's Function as a Media communication of Public Transportation
}

\section{Analisis Fungsi Twitter Sebagai Media Komunikasi Transportasi Publik}

\author{
Mohammad Jafar Loilatu ${ }^{1}$, Bambang $\operatorname{Irawan}^{2}$, Salahudin $^{3}$, Iradhad Taqwa Sihidi ${ }^{4}$ \\ ${ }^{1}$ Magister Ilmu Pemerintahan, Jusuf Kalla School of Government, Universitas Muhammadiyah \\ Yogyakarta, Jl. Brawijaya, Geblagan, Tamantirto, Kec. Kasihan, Bantul, Daerah Istimewa \\ Yogyakarta 55183* \\ Email: jafar.loilatu@gmail.com \\ ${ }^{2}$ Program Administrasi Publik, Universitas Mulawarman Kalimantan Timur, Jl. G. Tabur, Gn. \\ Kelua, Kec. Samarinda Ulu, Kota Samarinda, Kalimantan Timur 75117 \\ Email: bambangirawan@unmul.ac.id \\ ${ }^{3}$ Program Studi Ilmu Pemerintahan, Universitas Muhammadiyah Malang, Jl. Bendungan Sutami \\ No.188, Sumbersari, Kec. Lowokwaru, Kota Malang, Jawa Timur 65145 \\ Email: salahudin@umm.ac.id \\ ${ }^{4}$ Program Studi Ilmu Pemerintahan, Universitas Muhammadiyah Malang, Jl. Bendungan Sutami \\ No.188, Sumbersari, Kec. Lowokwaru, Kota Malang, Jawa Timur 65145 \\ Email:iradhad@umm.ac.id
}

Masuk tanggal : 22-07-2020, revisi tanggal : 04-11-2020, diterima untuk diterbitkan tanggal : 07-12-2020

\begin{abstract}
Social media plays a significant role in public services, one of which is public transport, while social media often promotes active participation and makes cities more adaptive by using social media. Public transport in Jakarta uses social media as a form of public contact in the provision of services. This study looks at the role of Jakarta's transport social media in delivering excellent information, this research looks at social media twitter accounts consisting of Mass Rapid Transit (MRT), Light Rapid Transit (LRT) and Bus Rapid Transit (BRT) accounts. The method used in this research is a quantitative approach to text analysis focused on Nvivo analysis methods. The phases of analysis using Nvivo begin with: (1) collection data, (2) import data, (3) coding data, (4) data classification, and (5) display data. The findings of this study replied that the social media twitter role in public transport in Jakarta has information features such as: disability rights information, route changes, traffic jams and services. The information provided by the MRT, LRT and $B R T$ twitter social media accounts depends on the activeness of the Twitter social media so that the information can be acknowledged by users of public transport. The flow of information generated by the MRT, LRT and BRT social media accounts through; (1) data sources, (2) collection data, (3) responses, and (4) public information provided by each Twitter account.
\end{abstract}

Keyword: communication, information, services, transportation, twitter

\begin{abstract}
Abstrak
Media sosial memiliki peran yang besar dalam pelayanan publik salah satunya transportasi publik, media sosial juga mendorong interaksi menjadi aktif dan menjadikan kota lebih
\end{abstract}


adaptif dengan menggunakan media sosial. Transportasi publik Jakarta menggunakan media sosial sebagai alat komunikasi publik dalam memberikan pelayanan. Penelitian ini melihat fungsi media sosial transportasi Jakarta dalam memberikan informasi pelayanan, analisis ini melihat akun media sosial twitter yang terdiri dari akun Mass Rapid Transit (MRT), Light Rapid Transit (LRT) dan Bus Rapid Transit (BRT). Metode dalam penelitian ini menggunakan pendekatan kuantitatif text analysis berbasis software dengan tools analisis Nvivo. Tahapan analisis menggunakan Nvivo dimulai dengan; (1) capturing data, (2) import data, (3) coding data, (4) klasifikasi data, dan (5) display data. Hasil dari penelitian ini menjawab bahwa fungsi media sosial twitter pada transportasi publik Jakarta memiliki karakteristik informasi seperti; informasi tentang hak disabilitas, perubahan rute, kemacetan, dan pelayanan. Informasi yang diberikan oleh akun media sosial twitter MRT, LRT, dan BRT bergantung pada keaktifan media sosial twitter, sehingga informasi tersebut dapat diterima oleh pengguna transportasi publik. Alur informasi yang disampaikan oleh akun media sosial MRT, LRT dan BRT melalui; (1) data sources, (2) processing data, (3) respon dan (4) informasi publik yang disampaikan oleh masing-masing akun twitter.

Kata Kunci: informasi, komunikasi, transportasi, pelayanan, twitter

\section{Pendahuluan}

Media sosial sebagai alat komunikasi manusia dan menjadi bagian dari teknologi informasi dan komunikasi (Muhammad Kashif Imran and Syed Muhammad Javed Iqbal, 2018). Media sosial atau web 2.0 berfungsi untuk memberikan informasi tentang kondisi yang sedang terjadi (Shvetsova, 2017), berdasarkan fungsi tersebut maka media sosial dan TIK mampu menghubungkan segala aspek antara manusia dengan kota (Tregua et al., 2014). Memahami fungsi media sosial yang sangat penting maka lembaga publik menggunakan TIK dan media sosial untuk mempromosikan pelayanan yang efektif (Bertot et al., 2016). Penggunaan media sosial pada organisasi publik dapat memberikan peran kepada masyarakat untuk berinteraksi secara tidak langsung (Kacem \& Abid, 2016a), sedangkan pada transportasi publik media sosial dapat digunakan bagi masyarakat untuk terlibat dalam perencanaan pelayanan transportasi sehingga pelayanan menjadi transparan dan efisien (Majumdar, 2017), atau sebagai media report pelayanan (Stone et al., 2018), sehingga menurut Flügge (2017) media sosial berfungsi untuk menghubungkan masyarakat melalui informasi.

Memahami bahwa media sosial memiliki banyak fungsi, maka transportasi Jakarta memanfaatkan media sosial sebagai media informasi dalam pelayanan publik (smartcity.jakarta.go.id). Sebagai kota besar dengan mobilitas yang tinggi maka media sosial menjadi sumber informasi untuk menjawab permasalahan pada kota (Shvetsova, 2017), mobilitas yang tinggi membutuhkan sistem transportasi yang baik khususnya dalam penyampaian informasi. Masyarakat dapat memastikan pelayanan transportasi publik berjalan, sebagaimana pandangan Majumdar (2017) bahwa penggunaan media sosial pada transportasi publik bertujuan untuk memberikan pelayanan dan informasi. Sistem transportasi Jakarta merupakan bagian dari penerapan smart city, dengan begitu perkembangan kota yang pesat didukung oleh informasi dan teknologi yang memadai (van den Buuse \& Kolk, 2019), sehingga media sosial menjadi bagian yang sangat penting bagi inisiasi 
Mohammad Jafar Loilatu, Bambang Irawan, Salahudin, Iradhad Taqwa Sihidi:

Analysis of Twitter's Function as a Media communication of Public Transportation

Analisis Fungsi Twitter Sebagai Media Komunikasi Transportasi Publik

smart city di Jakarta, Pemerintah Jakarta mendefinisikan media sosial sebagai alat dan sensor terhadap aktivitas manusia untuk mengetahui kondisi Jakarta (smartcity.jakarta.go.id). Penggunaan media sosial sebagai alat komunikasi kepada pengguna transportasi dengan tujuan agar terkoneksi dengan infrastruktur, model ini diartikan sebagai mobility integration yang menghubungkan dengan transportasi lain (Okarma \& Andriukaitis, 2019). Fungsi media sosial pada transportasi publik juga berfungsi sebagai alat evaluasi pelayanan transportasi (C. Cottrill et al., 2017; C. D. Cottrill \& Derrible, 2015)

Dalam beberapa penelitian terakhir menjelaskan fungsi media sosial berbeda-beda seperti pelayanan, kebijakan, evaluasi. Charalabidis et al (2014) menilai dalam menggunakan media sosial masyarakat dapat berpartisipasi meskipun secara pasif, dan pemerintah hanya bertugas untuk menyampaikan informasi melalui media sosial tentang apa yang sedang terjadi dalam sebuah kota. Analisis media sosial telah banyak dilakukan baik dalam pengambilan kebijakan pelayanan (Grubmüller et al., 2013) evaluasi kebijakan (Nurmandi et al., 2018), self branding (Elwani \& Kurniawan, 2020), analisis media sosial berkaitan dengan kondisi yang sedang terjadi (Nofrima et al., 2020) analisis media sosial dapat dilakukan dengan ragam pendekatan ilmiah tentang kondisi tertentu (Stieglitz et al., 2018a), dari beberapa penelitian yang dilakukan media sosial memiliki fungsi seperti; pelayanan, kebijakan, evaluasi dan komunikasi (Gil de Zúñiga \& Diehl, 2017; Grubmüller et al., 2013; Hess, 2019; Isep Parid Yahya, 2019; Salahudin et al., 2020; Stieglitz et al., 2018b).

Media sosial menawarkan kota yang lebih efisien dengan meningkatkan interaksi antara stakeholder dan masyarakat (Molinillo et al., 2019), dapat digunakan untuk komunikasi dua arah dan interaksi antara user, bagi organisasi interaksi pemangku kepentingan (Novianti \& Wulung, 2020; Salahudin et al., 2020) dan pemberi pelayanan dapat dilakukan dengan media sosial (Elving \& May Postma, 2017), media sosial berguna untuk pengawasan terhadap kota (Pezanowski et al., 2018), dengan melakukan identifikasi terhadap tempat, kejadian dan mentransfer informasi melalui media sosial secara real time, selain itu media sosial menampilkan informasi yang sangat bermanfaat bagi masyarakat karena banyak data yang ada di dalamnya. Berdasarkan beberapa penelitian di atas maka penelitian dengan melihat fungsi twitter pada transportasi publik belum dilakukan, sehingga penelitian ini bertujuan untuk mengisi batasan dalam penelitian sebelumnya dengan melihat fungsi twitter pada transportasi publik. Berdasarkan fungsi media sosial pula maka penelitian ini melihat apakah informasi yang diberikan berkaitan dengan pelayanan transportasi publik.

Jakarta memiliki sistem transportasi publik yang menghubungkan beberapa titik, sistem transportasi Jakarta didesain saling terhubung dengan transportasi lain. Transportasi Jakarta dalam penelitian ini terbagi menjadi tiga yaitu Bus Rapid Transit (BRT), Light Rapid Transit (LRT), dan Mass Rapid Transit (MRT). Ketiga sistem transportasi ini didesain dengan sistem Transit Oriented Development (TOD), TOD menjadi titik pemberhentian dari transportasi publik Jakarta sehingga sistem transportasi tersebut sebagai transportasi terintegrasi. Sebagai transportasi publik ketiga moda transportasi tersebut menggunakan media sosial sebagai alat komunikasi publik kepada pengguna transportasi publik Jakarta, fungsi dari media 
sosial transportasi publik adalah memberikan informasi secara realtime tentang pelayanan dan kondisi pelayanan transportasi publik.

Sebagai alat mobilitas transportasi publik menjadi solusi atas kepadatan dan mobilitas masyarakat Jakarta, sehingga hadirnya transportasi publik bertujuan untuk mengurangi kepadatan dan kemacetan. Media sosial twitter menjadi alat pendukung dalam penyampaian informasi transportasi publik agar masyarakat dapat menghindari kemacetan dengan informasi transportasi Jakarta yang real time Melalui akun resmi transportasi, informasi disampaikan berhubungan dengan pelayanan yang sedang diberikan. Tetapi untuk menjalan pelayanan tersebut maka perlu metode agar dapat dikendalikan, diakses dan memberikan ruang partisipasi (Mora \& Iglesias, 2017), transportasi publik tidak hanya memberikan informasi dan pelayanan pelayanan tetapi memastikan akses informasi dan layanan yang diberikan kepada masyarakat. Neto (2018) aksesibilitas tersebut sebagai hak masyarakat untuk terhubung dengan objek yang berbeda dan menggunakannya secara baik sesuai dengan tujuannya.

Berdasarkan latar belakang di atas maka rumusan masalah dalam penelitian ini adalah bagaimana fungsi media sosial pada transportasi publik dalam memberikan pelayanan. Sedangkan tujuan dalam penelitian ini melihat fungsi media sosial twitter pada transportasi publik dalam memberikan pelayanan melalui penyampaian informasi. Dengan melihat akun media sosial twitter transportasi publik BRT, MRT, dan LRT, ketiganya adalah transportasi massa yang menggunakan media sosial sebagai alat penyampai informasi untuk mendukung pelayanan.

\section{Metode Penelitian}

Penelitian ini menggunakan metode kuantitatif, metode kuantitatif digunakan untuk menjawab rumusan masalah penelitian dengan model quantitative text analysis (Klüver, 2009), analisis kuantitatif dalam penelitian ini bertujuan untuk mendeskripsikan hasil temuan dalam penelitian secara rinci (Roberts, 2000). Alat analisis dalam penelitian ini menggunakan Nvivo, Nvivo sebagai alat analisis yang menampilkan data dalam bentuk teks dan gambar melalui proses koding data (Bazeley, 2002; Muhtarom et al., 2017), atau computer-aided text analysis (Neuendorf \& Kumar, 2015). Penggunaan Nvivo sebagai alat analisis memiliki tahapan yang dimulai dengan; (1) capturing data, (2) import data, (3) koding data, (4) klasifikasi data, dan (5) menampilkan data (Brandão, 2015), dan hasil data koding dikomparasikan.

Capturing data menggunakan N-Capture (google chrome) dengan memilih akun twitter BRT, LRT dan MRT. Pemilihan ketiga akun twitter tersebut karena BRT, LRT dan MRT sebagai sistem transportasi yang terintegrasi yang menghungkan dengan fasilitas publik, sehingga informasi yang dismapikan oleh ketiga akun ini berkaitan dengan kondisi pelayanan seperti lokasi pemberhentian, waktu pelayanan, perubahan rute, dan kondisi ganguan, dimana informasi tersebut saling berkaitan. Import data dari hasil N-Capture ke dalam Nvivo. Coding data sebagai proses penerjemahan data dari akun twitter MRT, LRT, dan BRT atau text mining. Proses koding disesuaikan dengan dengan teori yang telah digunakan. 
Classifying data sebagai proses penerjemahan ulang dari data coding, proses classifying menggunakan crosstabulation Nvivo, crosstabulation sebagai proses perbandingan dari data masing-masing. Tahapan terakhir dalam proses analisis Nvivo adalah display data dalam bentuk grafik dan tabel, model analisis ini dalam Nvivo disebut sebagai five steps analysis (Woolf \& Silver, 2018).

\section{Hasil Penemuan dan Diskusi}

Objek dalam penelitian ini meliputi akun transportasi publik Jakarta yaitu; MRT, LRT, dan BRT. MRT adalah tipe transportasi dengan jumlah angkutan yang tinggi (www.jakartamrt.co.id), LRT adalah tipe transportasi massal dengan jumlah penumpang yang lebih banyak (lrt jakarta.co.id), sedangkan BRT adalah sistem transportasi dengan jumlah penumpang yang sedikit, tetapi dikembangkan untuk menghubungkan titik pemberhentian (transjakarta.co.id). Pengguna transportasi Jakarta memanfaatkan halte dan TOD sebagai titik integrasi antara ketiga moda transportasi publik. Ketiga moda, transportasi ini adalah bagian dari sistem transportasi Jakarta yang terintegrasi satu sama lain, baik dengan halte, koridor, tiket, dan sistem pelayanan, meskipun di bawah kendali operator yang berbeda. Dalam memberikan pelayanan khususnya informasi, ketiga mode transportasi ini menggunakan website, dan media sosial untuk menyampaikan informasi dan pelayanan yang bersifat online, media sosial memberikan kemudahan bagi MRT, untuk menyampaikan informasi kepada pengguna, media sosial sendiri bukan menjadi alat utama penyampaian informasi. Ketiga mode transportasi memiliki media penyampaian informasi yang varian, tetapi fokus penelitian ini melihat bagaimana pemanfaatan twitter dalam memberikan pelayanan transportasi publik.

\section{Fungsi Pelayanan}

Inklusif sebagai kesamaan akses terhadap pelayanan dan infrastruktur (Fattah, 2018), pelayanan transportasi publik Jakarta menggambarkan bentuk inkulifitas, Maftuhin (2017) inklusif sebagai bentuk penyedia pelayanan publik yang responsive terhadap setiap kelas masyarakat, atau sebagai pelayanan yang berkelanjutan dengan memanfaatkan teknologi (Kramers et al., 2014). Bahwa aksesibilitas fasilitas publik di dorong oleh teknologi yang modern salah satunya informasi yang update, seperti pandangan Kacem \& Abid (2016b) bahwa akses pelayanan tidak dapat dijangkau tanpa informasi yang cepat. Gambar (1) di bawah adalah bentuk pelayanan inklusif yang diberikan oleh transportasi Jakarta melalui penyampaian informasi. 


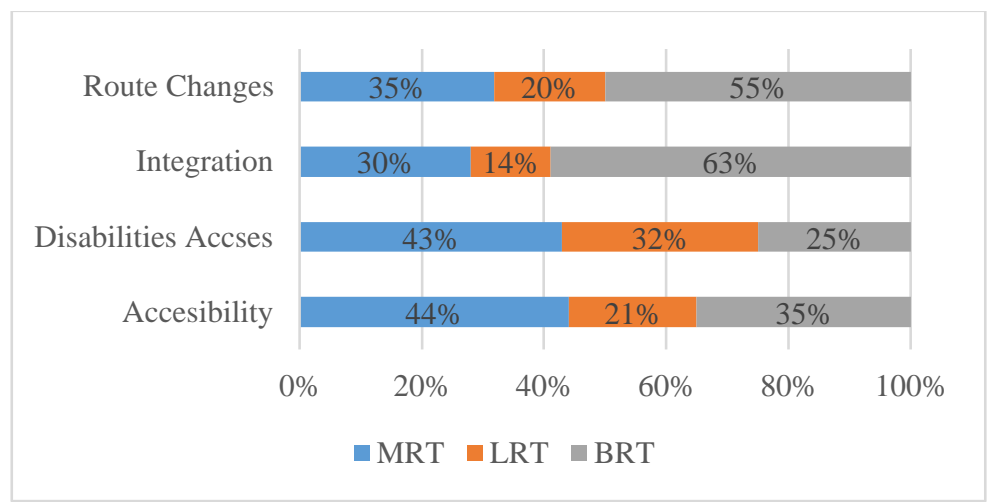

Gambar 1: Fungsi Pelayanan

(Sumber: Diolah dari Nvivo 12 Plus)

Gambar (1) menunjukan perbandingan inklusif service, ketiga moda transportasi, MRT aksesibilitas 44\%, disability akses 43\%, integrasi 30\%, dan perubahan rute $35 \%$. LRT aksesibilitas $21 \%$, disability akses $32 \%$, interaksi $14 \%$, perubahan rute 20\%. BRT Aksesibilitas 35\%, disability akses 25\%, integrasi 63\%, dan perubahan rute $55 \%$. Berdasarkan gambar (2), akun media sosial yang yang intens memberikan informasi tentang aksesibilitas adalah MRT, dan BRT. Disability akses MRT dan LRT. Integrasi BRT dan MRT, perubahan rute BRT dan LRT. Aspek inklusif service pada ketiga akun media twitter memiliki informasi yang berbeda-beda berdasarkan prioritas pelayanan yang diberikan. Artinya ketiga akun twitter mendukung pelayanan inklusif dari aspek yang berbeda-beda dengan informasi yang sesuai dengan model pelayanan transportasi.

Inklusif city adalah kota yang di dalamnya fasilitas publik dapat diakses secara bersama-sama baik itu difabel atau masyarakat biasa, sehingga dalam konsep smart city dikenal istilah inklusif city dan inklusif service. Inklusif service adalah bentuk pelayanan yang melihat masyarakat difabel, dan menyediakan fasilitas khusus bagi mereka yang berkebutuhan khusus, konsep ini dikenal sebagai inklusif service. Dalam pengelolaan transportasi publik Jakarta, inklusif service melihat pada kelompok yang berkebutuhan khusus, sehingga twitter BRT, LRT, dan MRT perlu menyampaikan informasi tentang penggunaan transportasi bagi difabel dan yang berkebutuhan khusus lainnya, selain itu twitter memberikan informasi tentang akses fasilitas publik bagi semua masyarakat.

Berdasarkan hasil coding di atas maka fungsi utama dari inklusif adalah aksesibilitas bagi masyarakat, informasi melalui media sosial mendorong pelayanan yang inklusif dapat diwujudkan. Merluci et al (2019) inklusif adalah ruang yang aktivitas dan mobilitas masyarakat secara terbuka dengan mendapatkan pelayanan, penghormatan, dan kesamaan derajat. Oleh kerana itu pendekatan pelayanan yang diberikan oleh transportasi Jakarta adalah pendekatan integrasi pelayanan, hal tersebut berkaitan erat dengan pelayanan inklusif (Jaiswal, 2017). Gambar 1 di atas menunjukan perbedaan informasi yang disampaikan oleh akun transportasi publik Jakarta baik MRT, LRT, atau BRT. 


\section{Fungsi Penyampaian Informasi Lalu Lintas}

Bagi kota-kota besar media sosial berfungsi sebagai city branding atas inovasi dan pelayanan. Kebutuhan terhadap informasi menjadi hal yang paling utama sehingga pengguna transportasi dengan mudah mengakses transportasi publik. Informasi yang disampaikan juga dapat dikendalikan jika terjadi perubahan, hal ini sesuai dengan informasi baru yang diterima dari pihak kedua atau ketiga tentang kondisi transportasi di Jakarta. Hämäläinen, (2019) transformasi tersebut membawa perubahan tentang kota yang saling terhubung, dengan memanfaatkan TIK, maka ITS dapat terhubung dengan sistem yang membantu menerjemahkan data data (T. Wang et al., 2019). Gambar (2) di bawah adalah fungsi twitter dalam penyampaian informasi lalu lintas.

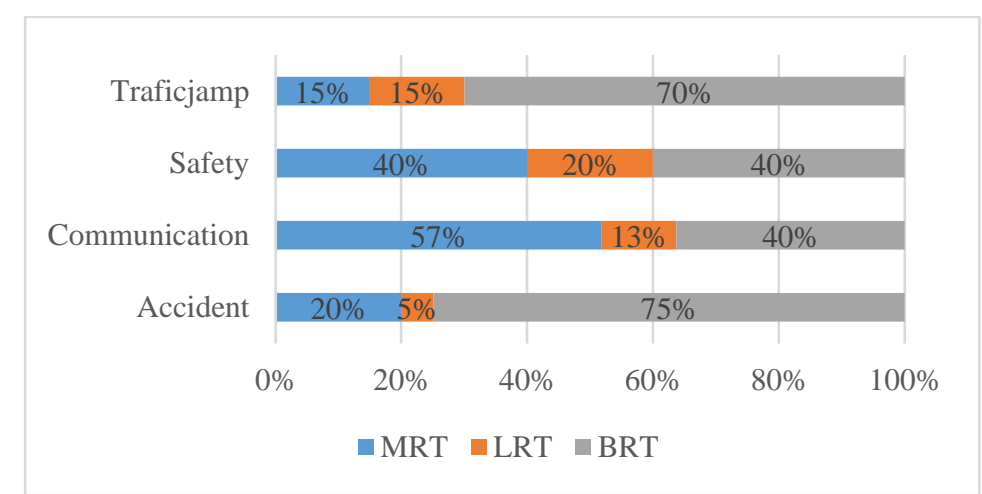

Gambar 2: Penyampaian Informasi Lalu Lintas (Sumber: Diolah dari Nvivo 12 Plus)

Informasi yang disampaikan oleh akun twitter BRT, LRT, dan MRT pada gambar di atas mengarah pada fungsi informasi dan komunikasi. MRT Kecelakaan $20 \%$, komunikasi 57\%, keselamatan 40\%, kemacetan 15\%. LRT kecelakaan 5\%, komunikasi $13 \%$, keselamatan 20\%, dan kemacetan 15\%. BRT Kecelakaan 75\%, komunikasi 40\%, keselamatan 40\%, kemacetan 70\%. Gambar 3 menjelaskan pada penyampaian informasi lalu lintas BRT lebih sering menyampaikan informasi seperti kemacetan, keselamatan, perubahan rute, komunikasi dan kecelakaan. MRT menyampaikan informasi yang berkaitan dengan komunikasi dan keselamatan, sedangkan LRT dengan fungsi yang lebih rendah dari keempat fungsi tersebut. Informasi yang disampaikan oleh BRT didasari oleh model pelayanan dengan rute yang berbeda-beda, dan lintasan yang bersebelahan dengan lintasan transportasi pribadi, sehingga informasi yang disampaikan berkisar pada kecelakan, kemacetan, dan perubahan rute akibat pembangunan atau kegiatan publik.

Word frequency pada gambar (3) dan (4) menunjukan informasi yang disampaikan oleh akun MRT dan LRT berkaitan dengan disability akses dan aksesibilitas, gambar (3) dan (4) informasi tentang disability akses tidak intensi disampaikan, tetapi informasi tentang disability access dengan kata kunci teman, sahabat, kami, lansia. Tetapi intensitas informasi yang disampaikan oleh akun LRT lebih rendah hal itu berdasarkan word frequency yang lebih sedikit pada gambar (4). Intensitas informasi tersebut mempengaruhi kualitas informasi yang akan disampaikan oleh akun LRT, Kousiouris et al., (2018) menilai dengan intensitas 
informasi yang rendah maka pelanggan akan berdampak karena pengguna transportasi tidak mengetahui jadwal, rute dan sistem pelayanan yang diberikan.

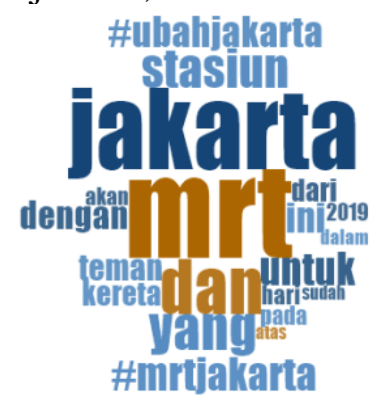

Gambar 3: Word Frequency MRT Jakarta

(Sumber: Diolah dari Nvivo 12 Plus)

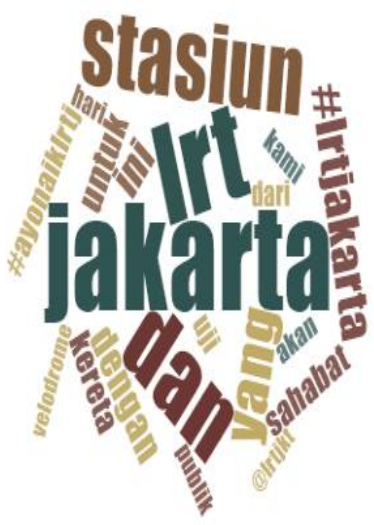

Gambar 4: Word Frequency LRT Jakarta

(Sumber: Diolah dari Nvivo 12 Plus)

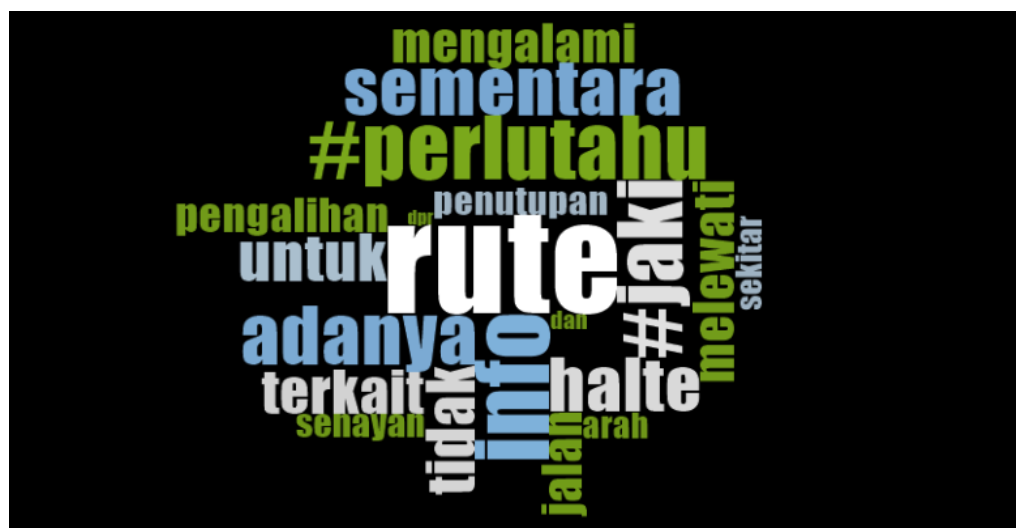

Gambar 5: Word Frequency BRT Jakarta

(Sumber: Diolah dari Nvivo 12 Plus)

Kota-kota besar mengintegrasikan informasi dari berbagai sumber (Kousiouris et al., 2018) sistem informasi yang dikelola oleh transportasi juga memanfaatkan informasi dari berbagai pengguna media sosial. Ebrahim \& Irani (2005) mengikuti cara pandang pelayanan sektor publik maka informasi yang disampaikan oleh transportasi Jakarta mendorong pelayanan transparan, efficient, 
information quality, service quality transparency (Sabani, Teng, and Thai 2019). Pada gambar 5 informasi yang disampaikan oleh akun ini berkaitan dengan aktivitas di atas dengan kata kunci, "mengalami", "pengalihan", "melewati", "adanya", "penutupan", "sekitar", "rute", dan "jalan".

Media sosial dan smart city adalah bagian yang tidak dapat terpisahkan, evolusi web 2.0 merubah wajah kota menjadi lebih modern dari sudut-sudut kota, informasi tentang sebuah kota juga dengan mudah diperoleh melalui media sosial, selain itu sebagai penyedia informasi media sosial sebagai ruang bagi masyarakat untuk mengambil peran dalam memberikan informasi (Kacem \& Abid, 2016a), informasi melalui media sosial dapat disampaikan kapan saja, bahwa masyarakat juga sebagai penyebar informasi dalam smart city, dalam penggunaan media sosial salah satu tujuan agar informasi dapat diperbaharui kapan saja, agar masyarakat mengetahui perubahan pelayanan yang sedang dilakukan oleh satu unit. Smart city menurut Chourabi et al., (2012) adalah kota yang terhubung dengan infrastruktur transportasi dengan menggunakan TIK, dengan keterhubungan infrastruktur maka sistem pelayanan bersifat integratif.

\section{Tipe Informasi}

Informasi yang disampaikan oleh akun transportasi sebagai bentuk informasi untuk membantuk opini tentang pelayanan transportasi publik Jakarta, tujuannya agar masyarakat dapat beralih dari transportasi pribadi ke transportasi publik. Tabel dibawah menjelaskan tipe hashtag transportasi MRT, LRT dan BRT.

Tabel 1. Hashtag Akun Media Sosial Twitter

\begin{tabular}{lll}
\hline Account & Hashtag & Precentage \\
\hline \multirow{4}{*}{ MRT } & \#Sambutmrtjakarta & $1,23 \%$ \\
\cline { 2 - 3 } & \#Jakartabersih & $0,53 \%$ \\
\cline { 2 - 3 } & \#Mrtjakarta & $43,23 \%$ \\
\cline { 2 - 3 } & \#Ubahjakarta & $39,72 \%$ \\
\cline { 2 - 3 } & \#AyonaikLRT & $19,20 \%$ \\
\hline \multirow{3}{*}{ LRT } & \#LRTJakarta & $27,90 \%$ \\
\cline { 2 - 3 } & \#LRTjkt & $11,96 \%$ \\
\cline { 2 - 3 } & \#Ujipubliklrt & $8,70 \%$ \\
\cline { 2 - 3 } & \#Lrtjkita & $3,26 \%$ \\
\cline { 2 - 3 } & \#Jelajahijakarta & $9,67 \%$ \\
\cline { 2 - 3 } & \#Yuknaiktije & $0,13 \%$ \\
\cline { 2 - 3 } BJakarta ramah bersepeda & $0,25 \%$ \\
& \#Jaki & $49,44 \%$ \\
\cline { 2 - 3 } & \#Perlutahhu & $49,44 \%$ \\
\hline
\end{tabular}

Sumber: Diolah dari Nvivo 12 Plus 
Informasi yang disampaikan oleh akun MRT Jakarta menggunakan beberapa hashtag tentang tujuan penggunaan MRT, seperti \#MrtJakarta 43,23\%, \#UbahJakarta 39,72\%, dan \#Jelajahi Jakarta 9,67\%. Tipe informasi yang disampaikan oleh akun ini tidak begitu intens. Sedangkan pada akun LRT hashtag sangat bervariatif dimulai dengan \#AyoNaikLrt 19,20\%, \#LrtJakarta 27,90\%, dan \#LRTJkt 11,86\%, meskipun hashtag bervariatif tetapi informasi yang disampaikan oleh akun LRT tidak begitu intens seperti BRT. Akun BRT dengan dua hashtag dominan yaitu \#Jaki 49,44\% dan \#Perlutahu 49,44\%, tweet BRT berisi tentang informasi perubahan rute Transjakarta, panduan penggunaan Transjakarta. Informasi yang disampaikan oleh ketiga akun memiliki perbedaan masing-masing, hal ini bergantung pada penyedia layanan transportasi publik. Informasi yang disampaikan ketiga akun ini dilihat berdasarkan hashtag, dengan tujuan agar kriteria informasi dapat diketahui. Fungsi hashtag untuk mempopulerkan informasi tentang transportasi publik sehingga masyarakat dapat beralih dari transportasi pribadi dan menggunakan transportasi publik.

Informasi yang disampaikan tidak memiliki kriteria informasi seperti perubahan rute, pedoman penggunaan transportasi publik atau peta BRT Jakarta. Kedua akun LRT dan MRT memiliki kesamaan dalam penyampaian informasi, menggunakan hashtag yang cukup banyak tetapi informasi yang disampaikan tidak berkaitan dengan pelayanan yang sedang diberikan. Agar dapat memahami isi dan muatan informasi yang disampaikan oleh ketiga akun tersebut, maka penelitian menggunakan analisis text search untuk mencari inti kata dalam setiap informasi yang disampaikan oleh akun twitter BRT, LRT, dan MRT, kata yang dipilih mewakili informasi akun twitter ketiga transportasi Jakarta.

Tabel 2. Word List Berdasarkan Text Search

\begin{tabular}{ll}
\hline Fungsi & Word List \\
\hline Pengalihan Rute & perubahan, keberangkatan, kedatangan, jadwal, pengalihan. \\
\hline Integrasi & $\begin{array}{l}\text { rute, perubahan, kedatangan dari, antara moda transportasi, } \\
\text { infrastruktur, }\end{array}$ \\
\hline Disability & $\begin{array}{l}\text { ramah, sahabat, teman, kursi prioritas, kenyamanan, lansia, anak, } \\
\text { ruang khusus, ibu hamil }\end{array}$ \\
\hline Inklusif & ruang khusus, anak, lansia, kenyaman, masyarakat. \\
\hline Traficjamp & pentupan, pengaliha, melewati \\
\hline Safety & keselamatan, menggunakan, \\
\hline Accident & kecelakaan, adanya, melewati.
\end{tabular}

Sumber: Diolah dari Nvivo 12 Plus

Tweet tentang pelayanan melalui penyampaian informasi menunjukan bahwa sistem transportasi di Jakarta terintegrasi antar mode, sehingga informasi yang disampaikan harus sesuai dengan perubahan jadwal dan lokasi pemberhentian setiap mode transportasi. Selain itu transportasi Jakarta juga menghubungkan setiap halte dan pemberhentian lainnya, sehingga management informasi yang baik dapat mempengaruhi kualitas pelayanan. Text search pada tabel (2) adalah list word yang menunjukan informasi yang disampaikan oleh akun twitter transportasi Jakarta. Seperti yang dijelaskan pada gambar (1) dan (2) dari hasil coding, maka interaksi dan pengalihan lebih dominan pada akun twitter BRT, disability dan inklusif akun 
MRT dan LRT. Tabel (2) adalah word list yang mewakili kata kunci dari informasi yang disampaikan, informasi tersebut tergantung pada layanan dan pengguna transportasi.

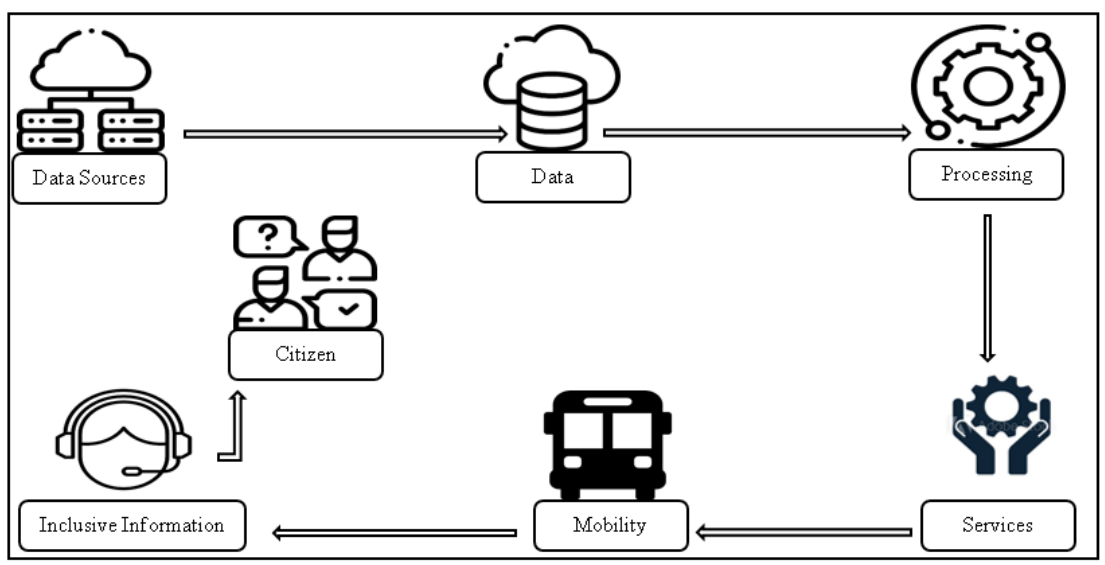

Gambar 6: Alur Informasi Traportasi Jakarta

Ilustrasi di atas adalah alur informasi yang disampaikan oleh akun twitter MRT, LRT dan BRT. Media sosial twitter bertujuan untuk menghubungkan masyarakat dengan fasilitas publik dan ruang publik, agar dapat terhubung dengan fasilitas tersebut masyarakat terlebih dahulu terhubung dengan informasi tentang pelayanan tersebut. Hämäläinen (2019) masyarakat urban terhubung satu dengan fasilitas publik karena mobilitas yang tinggi, sehingga perlu informasi yang intens untuk mempermudah mobilitas masyarakat urban, melalui transportasi publik (Y. Wang et al., 2016). Penggunaan twitter sebagai media komunikasi pelayanan transportasi dapat diberikan secara baik dengan memanfaatkan informasi melalui twitter. Informasi mendukung Transit Development Oriented (TOD) yang berfungsi menghubungkan fasilitas dan pemberhentian yang mudah diakses.

Pada gambar (6) alur informasi yang disampaikan oleh akun twitter transportasi Jakarta sampai pada model inclusive information. Inklusif information adalah informasi yang berkaitan dengan hak pengguna transportasi publik Jakarta yang harus disampaikan melalui akun resmi transportasi Jakarta. Penggunaan media sosial twitter oleh ketiga penyedia layanan transportasi publik tersebut telah sesuai sebagaimana prinsip penggunaan TIK, Kacem \& Abid, (2016) bahwa akses informasi pelayanan dengan TIK mudah untuk disampaikan dan diterima bagi masyarakat, dengan begitu perlu pemanfaatan media sosial. Mora \& Iglesias (2017) model seperti ini dapat disebut sebagai urban informasi yang memberikan informasi tentang lokasi, rute pelayanan, jadalwa pelayanan yang terkoneksi secara langsung melalui mobile phone, dengan model informasi seperti ini dan berjalan secara baik dalam menghubungkan aspek pelayanan (Jaiswal, 2017).

\section{Simpulan}

Berdasarkan analisis di atas maka penelitian ini menyimpulkan bahwa media sosial twitter transportasi publik Jakarta memiliki fungsi yang berbeda-beda. MRT pada fungsi inklusif dominan pada aspek disabilitas dan aksesibilitas, aspek 
pelayanan informasi komunikasi dan keselamatan. LRT hanya pada akses disabilitas. BRT aspek pelayanan inklusif perubahan rute dan integrasi rute, sedangkan informasi BRT aktif dalam memberikan informasi kemacetan, kecelakaan, keselamatan dan komunikasi. Berdasarkan hashtag akun MRT dan LRT lebih variatif sedangkan akun BRT konsisten pada dua hashtag. Sumber data dari media sosial berasal dari pengguna transportasi dan infrastruktur seperti cctv, gps yang terhubung dengan sistem informasi transportasi jakarta, dengan begitu transportasi publik jakarta yang memberikan report tentang kondisi pelayanan berdasarkan data-data tersebut. Akun media sosial twitter transportasi Jakarta memiliki fungsi dalam penyampaian informasi yang berbeda-beda.

\section{Ucapan Terimakasih}

Tim penulis mengucapkan terimakasih kepada Program Studi Magister Ilmu Pemerintahan, Jusuf Kalla School of Government Universitas Muhammdiyah Yogyakarta.

\section{Daftar Pustaka}

Bazeley, P. (2002). The evolution of a project involving an integrated analysis of structured qualitative and quantitative data: From N3 to NVivo. International Journal of Social Research Methodology, 5(3), 229-243. https://doi.org/10.1080/13645570210146285

Bertot, J., Estevez, E., \& Janowski, T. (2016). Universal and contextualized public services: Digital public service innovation framework. Government Information Quarterly, 33(2), 211-222. https://doi.org/10.1016/j.giq.2016.05.004

Brandão, C. (2015). P. Bazeley and K. Jackson, Qualitative Data Analysis with NVivo (2nd ed.) . Qualitative Research in Psychology, 12(4), 492-494. https://doi.org/10.1080/14780887.2014.992750

Charalabidis, Y., Loukis, E. N., Androutsopoulou, A., Karkaletsis, V., \& Triantafillou, A. (2014). Passive crowdsourcing in government using social media. Transforming Government: People, Process and Policy, 8(2), 283308. https://doi.org/10.1108/TG-09-2013-0035

Chourabi, H., Nam, T., Walker, S., Gil-Garcia, J. R., Mellouli, S., Nahon, K., Pardo, T. A., \& Scholl, H. J. (2012). Understanding smart cities: An integrative framework. Proceedings of the Annual Hawaii International Conference on System Sciences, 2289-2297. https://doi.org/10.1109/HICSS.2012.615

Cottrill, C. D., \& Derrible, S. (2015). Leveraging Big Data for the Development of Transport Sustainability Indicators. Journal of Urban Technology, 22(1), 45-64. https://doi.org/10.1080/10630732.2014.942094

Cottrill, C., Gault, P., Yeboah, G., Nelson, J. D., Anable, J., \& Budd, T. (2017). Tweeting Transit: An examination of social media strategies for transport information management during a large event. Transportation Research Part C: Emerging Technologies, 77, 421-432. https://doi.org/10.1016/j.trc.2017.02.008 
Ebrahim, Z., \& Irani, Z. (2005). E-government adoption: Architecture and barriers. Business Process Management Journal, 11(5), 589-611. https://doi.org/10.1108/14637150510619902

Elving, W. J. L., \& May Postma, R. (2017). Social Media: The Dialogue Myth? How Organizations Use Social Media for Stakeholder Dialogue. Public Relations and Communication Management, 2(1), 123-141. https://doi.org/10.1108/s2398-391420170000002011

Elwani, R. S., \& Kurniawan, F. (2020). Pemanfaatan Media Sosial Dalam Pemasaran Sosial Bagi Remaja. Jurnal Komunikasi, 12(1), 64. https://doi.org/10.24912/jk.v12i1.6654

Fattah, K. N. (2018). Towards inclusive cities in Bangladesh: Are policies sufficient to promote inclusiveness? December.

Flügge, B. (2017). Smart mobility - connecting everyone: Trends, concepts and best practices. Smart Mobility - Connecting Everyone: Trends, Concepts and Best Practices, 1-293. https://doi.org/10.1007/978-3-658-15622-0

Gil de Zúñiga, H., \& Diehl, T. (2017). Citizenship, Social Media, and Big Data: Current and Future Research in the Social Sciences. Social Science Computer Review, 35(1), 3-9. https://doi.org/10.1177/0894439315619589

Grubmüller, V., Götsch, K., \& Krieger, B. (2013). Social media analytics for future oriented policy making. European Journal of Futures Research, 1(1), 1-9. https://doi.org/10.1007/s40309-013-0020-7

Hämäläinen, M. (2019). A Framework for a Smart City Design: Digital Transformation in the Helsinki Smart City. September 2019, 63-86. https://doi.org/10.1007/978-3-030-23604-5_5

Hess, D. J. (2019). Coalitions, framing, and the politics of energy transitions: Local democracy and community choice in California. Energy Research and Social Science, 50(July 2018), 38-50. https://doi.org/10.1016/j.erss.2018.11.013

Isep Parid Yahya. (2019). Media Framing vs Framing by Politician ( A Study About the Mutual Influences Between Media Frames and Frames by Politicians During the Political Campaign A Head of Jakarta Governor Election ). Jurnal Studi Pemerintahan, 10(1), 1-18.

Jaiswal, P. (2017). Inclusive Planning Smart Solution for City Design. International Journal on Emerging Technologies, 8(1), 521-523.

Kacem, A., \& Abid, I. H. (2016b). Towards Improving e-Government Services Using Social Media- Based Citizen's Profile Investigation. ICEGOV, 3, 187-190. https://doi.org/10.1145/2910019.2910029

Klüver, H. (2009). Measuring interest group influence using quantitative text analysis. European Union Politics, 10(4), 535-549. https://doi.org/10.1177/1465116509346782

Kousiouris, G., Akbar, A., Sancho, J., Ta-shma, P., Psychas, A., Kyriazis, D., \& Varvarigou, T. (2018). An integrated information lifecycle management framework for exploiting social network data to identify dynamic large crowd concentration events in smart cities applications. Future Generation Computer Systems, 78 , 516-530. https://doi.org/10.1016/j.future.2017.07.026 
Kramers, A., Höjer, M., \& Lövehagen, N. (2014). Smart Sustainable Cities e Exploring ICT Solutions for Reduced Energy Use in Cities. Enviroemntal Modelling \& Software, 1-11. https://doi.org/10.1016/j.envsoft.2013.12.019

Maftuhin, A. (2017). Defining Inclusive City: Origin, Theories, and Indicators. Tata Loka, 19(2), 93-103. https://doi.org/10.14710/tataloka.19.2.93-103

Majumdar, S. R. (2017). The case of public involvement in transportation planning using social media. Case Studies on Transport Policy, 5(1), 121-133. https://doi.org/10.1016/j.cstp.2016.11.002

Merluci, I., Eds, C. S., \& Bet, C. (2019). Understanding the complexity of inclusive public space design - Reflections on the case study of Slovenia (Issue January).

Molinillo, S., Anaya-Sánchez, R., Morrison, A. M., \& Coca-Stefaniak, J. A. (2019). Smart city communication via social media: Analysing residents' and visitors' engagement. Cities, 94(December 2018), 247-255. https://doi.org/10.1016/j.cities.2019.06.003

Mora, H. M., \& Iglesias, V. G. (2017). Improving Urban Accessibility: A Methodology for Urban Dynamics Analysis in Smart, Sustainable and Inclusive Cities. 11th International Conference on Urban Regeneration and Sustainability (Sustainable City 2016) Www.Witconferences.Com, 12(3), 357-367. https://doi.org/10.2495/SDP-V12-N3-357-367

Muhammad Kashif Imran and Syed Muhammad Javed Iqbal. (2018). Does social media promote knowledge exchange? A qualitative insight. Emeralldisight, 290215, 573-277. https://doi.org/10.1108/MD-05-2017-0477

Muhtarom, Murtianto, Y. H., \& Sutrisno. (2017). Thinking process of students with high-mathematics ability: (a study on QSR NVivo 11-assisted data analysis). International Journal of Applied Engineering Research, 12(17), 6934-6940.

Neto, J. S. D. O. (2018). Inclusive Smart Cities: Theory and Tools to Imporve the Experience of People with Disabilities in Urban Places.

Neuendorf, K. A., \& Kumar, A. (2015). Emerging trends in content analysis. The International Encyclopedia of Political Communication, 1(May), 1-10. https://doi.org/10.1002/9781118541555.wbiepc065

Nofrima, S., Nurmandi, A., Kusuma Dewi, D., \& Salahudin, S. (2020). Cyberactivism on the dissemination of \#Gejayanmemanggil: Yogyakarta's student movement. Jurnal Studi Komunikasi (Indonesian Journal of Communications Studies), 4(1), 103. https://doi.org/10.25139/jsk.v4i1.2091

Novianti, E., \& Wulung, S. R. P. (2020). Implementasi Komunikasi Daring dalam Menunjang Jawa Barat sebagai Destinasi Pariwisata Cerdas. Jurnal Komunikasi, 12(1), 53. https://doi.org/10.24912/jk.v12i1.6971

Nurmandi, A., Almarez, D., Roengtam, S., Salahudin, Jovita, H. D., Kusuma Dewi, D. S., \& Efendi, D. (2018). To what extent is social media used in city government policy making? Case studies in three asean cities. Public Policy and Administration, 17(4), 600-618. https://doi.org/10.13165/VPA-18-174-08

Okarma, K., \& Andriukaitis, D. (2019). Sensors in Intelligent Transportation Systems. Journal of Advanced Transportation, 2019, 1-8. 
Pezanowski, S., MacEachren, A. M., Savelyev, A., \& Robinson, A. C. (2018). SensePlace 3: a geovisual framework to analyze place-time-attribute information in social media. Cartography and Geographic Information Science, 45(5), 420-437. https://doi.org/10.1080/15230406.2017.1370391

Roberts, C. W. (2000). A Conceptual Framework for Quantitative Text Analysis. Quality I\& Quantity, 34(3), 259-274. http://dx.doi.org/10.1023/A:1004780007748

Salahudin, Nurmandi, A., Jubba, H., Qodir, Z., Jainuri, \& Paryanto. (2020). Islamic Political Polarisation on Social Media During the 2019 Presidential Election in Indonesia. Asian Affairs. https://doi.org/10.1080/03068374.2020.1812929

Shvetsova, O. A. (2017). Smart education in high school: New perspectives in global world. Proceedings of the 2017 International Conference "Quality Management, Transport and Information Security, Information Technologies", IT and QM and IS 2017, 688-691. https://doi.org/10.1109/ITMQIS.2017.8085917

Stieglitz, S., Mirbabaie, M., Ross, B., \& Neuberger, C. (2018a). Social media analytics - Challenges in topic discovery, data collection, and data preparation. International Journal of Information Management, 39(December 2017), 156-168. https://doi.org/10.1016/j.ijinfomgt.2017.12.002

Stone, M., Knapper, J., Evans, G., \& Aravopoulou, E. (2018). Information management in the smart city. Bottom Line, 31(3-4), 234-249. https://doi.org/10.1108/BL-07-2018-0033

Tregua, M., Auria, A. D., \& Bifulco, F. (2014). Digital City vs . Smart City : a fuzzy debate. Proceedings in Scientific Conference 9., 2014(March), 393-399.

van den Buuse, D., \& Kolk, A. (2019). An exploration of smart city approaches by international ICT firms. Technological Forecasting and Social Change, 142(February), 220-234. https://doi.org/10.1016/j.techfore.2018.07.029

Wang, T., Hussain, A., Bhutta, M. N. M., \& Cao, Y. (2019). Enabling bidirectional traffic mobility for ITS simulation in smart city environments. Future Generation Computer Systems, 92, 342-356. https://doi.org/10.1016/j.future.2018.10.015

Wang, Y., Wang, T., Ye, X., Zhu, J., \& Lee, J. (2016). Using social media for emergency response and urban sustainability: A case study of the 2012 Beijing rainstorm. Sustainability (Switzerland), 8(1), 1-17. https://doi.org/10.3390/su8010025

Woolf, N. H., \& Silver, C. (2018). Qualitative Analysis Using Nvivo, The Five Level QDA Method. In Routledge (pp. 1-1235). Routledge. 